\title{
Off-Design Reynolds Number Effects for a Supersonic Transport
}

\author{
Lewis R. Owens ${ }^{\star}$, Richard A. Wahls ${ }^{\dagger}$, and S. Melissa Rivers
}

NASA Langley Research Center, Hampton, VA 23681-2199

\begin{abstract}
A high Reynolds number wind tunnel test was conducted to assess Reynolds number effects on the aerodynamic performance characteristics of a realistic, secondgeneration supersonic transport concept. The tests included longitudinal studies at transonic and low-speed, high-lift conditions across a range of chord Reynolds numbers (8 million to 120 million). Results presented focus on Reynolds number and static aeroelastic sensitivities at Mach 0.30 and 0.90 for a configuration without a tail. Static aeroelastic effects, which mask Reynolds number effects, were observed. Reynolds number effects were generally small and the drag data followed established trends of skin friction as a function of Reynolds number. A more nose-down pitching moment was produced as Reynolds number increased because of an outward movement of the inboard leading-edge separation at constant angles of attack. This study extends the existing Reynolds number database for supersonic transports operating at off-design conditions.
\end{abstract}

\footnotetext{
* Aerospace Engineer, Flow Physics and Control Branch, Senior Member, AIAA

${ }^{\dagger}$ Assistant Head, Configuration Aerodynamics Branch, Associate Fellow, AIAA

Aerospace Engineer, Configuration Aerodynamics Branch, Member, AIAA
} 


\section{NOMENCLATURE}

AR aspect ratio

b wing span, inches

BL butt-line, model coordinates, inches

$\mathrm{Cl}_{95} \quad 95 \%$ confidence interval

c local chord length, inches

$C_{D} \quad$ drag coefficient

$\mathrm{C}_{\mathrm{L}} \quad$ lift coefficient

$\mathrm{C}_{\mathrm{M}}$ pitching-moment coefficient referenced to 0.50 mac

$\mathrm{C}_{\mathrm{p}} \quad$ pressure coefficient

FS fuselage station, model coordinates, inches

M Mach number

mac mean aerodynamic chord, inches

nac engine nacelle

$\mathrm{P}_{\mathrm{T}} \quad$ total pressure, psi

q dynamic pressure, psf

$r \quad$ local leading-edge radius, inches

Rn Reynolds number based on mac

S wing reference area, square inches

$\mathrm{T}_{\mathrm{T}} \quad$ total temperature, degrees Fahrenheit

$t_{\max } \quad$ local maximum airfoil thickness, inches 
WL waterline, model coordinates, inches

$\alpha \quad$ angle of attack, degrees

$\eta \quad$ nondimensional semi-span station

$\theta \quad$ sectional wing twist change, relative to wind-off twist, degrees

\section{INTRODUCTION}

Ground-to-flight scaling remains one of the challenges facing today's designers of aerospace vehicles. The goal of ground-to-flight scaling is the preflight prediction of aerodynamic characteristics with sufficient accuracy to meet both performance guarantees and certification requirements. Specific challenges, experiences, and suggested approaches for ground-to-flight scaling have been documented extensively over the years for a variety of vehicle classes. ${ }^{1,2}$ Reynolds number effects are among many of the factors affecting successful ground-to-flight scaling. ${ }^{3-6}$ The Reynolds number is the ratio of inertial to viscous forces and is the primary aerodynamic scaling parameter used to relate sub-scale wind tunnel models to full-scale aircraft in flight. The challenge of Reynolds number scaling increases with the size of a full-scale aircraft as the Reynolds number increment between that obtainable in conventional wind tunnels and flight conditions expands. Additionally, the challenge for both wind tunnel and computational approaches increases as flow features become dominated by viscoussensitive phenomena such as boundary-layer transition, shock/boundary-layer interaction, and separation onset and progression. 
The supersonic transport configuration geometry tested was provided by Boeing and represented a Mach 2.4, 300-passenger aircraft design with a 5000 nautical mile range. The current study, one of many studies utilizing this reference configuration during NASA's High-Speed Research ${ }^{7}$, targeted improved understanding and prediction of scale effects to reduce risk in the design and development of future vehicles by identifying physical features and associated flow physics of this vehicle class that could contribute to the aerodynamic differences between a full-scale flight vehicle and windtunnel models of various scale. A specific focus was directed towards the off-design challenges $^{8}$ of efficient transonic cruise and acceleration and quiet high-performance take-off and landing. For this class of vehicle, a nominal mission profile would require minimum chord Reynolds numbers of approximately 130 million at $\mathrm{M}=0.30$ and 120 million at $\mathrm{M}=0.90 .^{9,10}$ Conventional ground facilities with appropriately sized models of this type cannot obtain chord Reynolds numbers any higher than about 10 to 30 million.

A series of wind tunnel tests was performed in the National Transonic Facility (NTF) at the NASA Langley Research Center (LaRC) across a wide range of Reynolds numbers from that available in conventional wind tunnels to near flight conditions at subsonic and transonic Mach numbers. The tests included longitudinal and lateral/directional studies with and without a tail at transonic and low-speed, high-lift conditions. This paper includes results focused on the Reynolds number sensitivities of the longitudinal characteristics at subsonic, off-design conditions (Mach 0.30 and 0.90 ) representative of take-off and transonic cruise for the configuration without a tail. 


\section{EXPERIMENTAL APPROACH}

\section{Model Description}

The wind-tunnel model is a $2.2 \%$ scale representation of the High Speed Research Program ${ }^{7}$ baseline configuration known as Reference $\mathrm{H}$. This paper focuses on results obtained for the wing/body configuration with the body truncated slightly aft of the wing trailing edge. Figure 1a shows a planform drawing of the model with wing pressure taps and reference locations noted. The model has a cranked-delta wing planform with an aspect ratio of 2.367, a span of 34.22 inches, and a mean aerodynamic chord of 22.71 inches. The inboard wing $(\eta \leq 0.522)$ has a blunt $(r / c \sim$ 0.0025 to 0.0030 ) subsonic leading edge with a sweep change from 76 to 68.5 degrees at $\eta=0.226$, a twist varying from approximately 1 degree near $\eta=0.10$ to -2 degrees near $\eta=0.50$, and variable thickness ratio $\left(t_{\max } / c\right)$ from 0.043 to 0.024 . The outboard, supersonic leading edge is sharp, swept 48 degrees, has a constant twist of -1.6 degrees for $\eta \geq 0.65$, and a constant thickness ratio of 0.024 . The reference area for the model is 494.78 square inches. Table 1 provides several key ratios relating the model size to the NTF test section. The model size was selected to minimize support system and wall interference effects.

The model was designed and constructed specifically for testing in the cryogenic, pressurized conditions of the NTF, where dynamic pressures reached approximately 2700 psf during these tests at transonic conditions; the unloaded model shape was that of the Mach 2.4 cruise, design point. The model was built of maraging steel with a 
surface finish of 8 - $16 \mu$-inches (root mean square) and a contour tolerance of \pm 0.005 inches. A photograph of the model is shown in figure $1 \mathrm{~b}$ mounted in the NTF test section on a straight support sting; this sting mounts to a 6-degree offset stub sting, which in turn mounts to the facility arcsector resulting in a model angle-of-attack range from -4 to 24 degrees.

The model has multiple inboard leading and trailing edge parts, multiple outboard wing panels each with different leading and trailing edge deflections, and four detachable, 8.43 inch long, constant internal diameter (1.236 inches), circular flowthrough nacelles with boundary-layer diverters located between the wing and nacelle. The inboard nacelles are rigged with toe-in and pitch (nose down) angles of 1 and 4.17 degrees, respectively; the outboard nacelles are rigged with toe-in and pitch angles of 2.4 and 2.84 degrees, respectively. The multiple leading and trailing edge parts in combination with the multiple outboard panels enabled testing of a variety of configurations including the baseline (supersonic cruise), take-off, landing, stall recovery, and transonic cruise configurations as defined in table 2.

The model was instrumented with 48 forebody pressures distributed circumferentially at two fuselage stations and 146 wing pressures distributed in both spanwise and chordwise rows on the starboard upper and port lower surfaces of the wing, as shown in figure 1a. Additionally, one inboard and one outboard nacelle were instrumented with an internal Preston tube, and 6 nacelle base pressure taps enabling correction for nacelle internal and base drag effects. Further details about the 
instrumentation, data reduction and corrections are presented in references 9,10 , and 15 through 18 . Additional test and facility details are included in references 9 through 14.

\section{$\underline{\text { Test Conditions }}$}

The NTF enables testing across a wide range of Reynolds numbers from that available in conventional wind tunnels to near flight conditions at subsonic and transonic Mach numbers. Tests of the supersonic transport model spanned Mach numbers from 0.30 to 1.10 , and chord Reynolds numbers from 8 million to 120 million based on the mean aerodynamic chord. Figure 2 provides the NTF operational envelopes for Mach 0.30 and 0.90 and each show the specific test points.

The goals of assessing Reynolds number scale effects and extrapolating to flight conditions required a series of intermediate conditions to better identify the trends. As seen in figure 2, the desired Reynolds number range could not be covered using a constant total pressure (dynamic pressure). However, the independent control of total pressure, total temperature, and fan speed in the NTF allow the isolation of viscous (Reynolds number) effects, static aeroelastic (dynamic pressure) effects, and compressibility (Mach) effects. Several conditions are used to isolate static aeroelastic effects from the viscous effects for Mach 0.30 and 0.90 as shown in figure 2. During Reynolds number sweeps, the ratio of dynamic pressure $(q)$ to the model material modulus of elasticity $(E)$ is held constant. This is done to maintain a constant static aeroelastic state $(q / E)$ due to the variability of the model material modulus of elasticity

7 
over the temperature range of the NTF. Note that constant q/E was not maintained for the two lowest Reynolds number conditions at Mach 0.30 due to the use of air rather than nitrogen. However, the aeroelastic adjustment methodology (as explained in the Results \& Discussion section) is sufficient to provide the Reynolds number effects at this lower dynamic pressure level.

\section{Boundary-Layer Transition}

Boundary-layer transition on the wing was allowed to occur naturally, in general, to observe transition effects over the complete Reynolds number range. Limited data was acquired with a forced transition pattern on the wing at low Reynolds number test conditions. The wing boundary-layer tripping pattern consisted of 0.125 inches wide carborundum grit strips that were placed on both the upper and lower wing surfaces. These grit strips were locally parallel to the wing leading edge and were placed 0.625 inches (measured stream-wise) downstream of the wing leading edge. Transition was consistently fixed on the forebody with a ring of carborundum grit located 1.5 inches from the nose, and on the nacelle internal surface to facilitate the internal nacelle drag correction; this approach was applied at all test conditions. All trips were sized and located based on the criteria of reference 19 .

\section{RESULTS \& DISCUSSION}

Figure 3 shows representative data for the baseline, take-off, and transonic cruise configurations at low and high Reynolds numbers, and is provided to indicate the general, longitudinal aerodynamic characteristics of the wing/body configuration. The 
data presented in figure 3 include the combined effects of different flap configurations, static aeroelastic deformation, and Reynolds number. The discussion of the results will address static aeroelastic effects and the adjustments to isolate the Reynolds number (viscous) effects for a given configuration. In these discussions, the angles of attack chosen correspond to take-off ( $\alpha=9$ degrees), transonic cruise ( $\alpha=5$ degrees), and minimum drag ( $\alpha=1.1$ degrees) conditions.

\section{Experimental Uncertainty}

Short-term data repeatability (within test / Mach series) is quantified in terms of a $95 \%$ confidence interval. ${ }^{20}$ The $95 \%$ confidence interval is interpreted as the bounds about an estimated mean (average of multiple, repeat polars) that encompasses the true mean value with a chance of $95 \%$. Examples of the short-term repeatability of longitudinal aerodynamic data are shown in references 9 and 10. For reference, the average $95 \%$ confidence intervals for $C_{L}, C_{D}$ and $C_{m}$ are approximately $\pm 0.002, \pm 0.0003$ and \pm 0.0005 , respectively, and are given here as an uncertainty estimate.

The angle-of-attack measurement was made with an internal, heated accelerometer package; quoted accuracy of the package is estimated to be \pm 0.01 degrees. ${ }^{17}$ Wing twist measurements were made using a video model deformation system. ${ }^{18}$ The system provided sectional twist change data relative to the wind-off shape with a quoted accuracy of \pm 0.1 degrees.

The tunnel Mach number, dynamic pressure and Reynolds number have uncertainty levels of approximately $\pm 0.002, \pm 1.5 \%$ of reading and \pm 0.5 million, 
respectively. Finally, the wing pressure measurements had an uncertainty level estimated to be within $\pm 1.5 \%$ of the pressure coefficient value.

\section{Static Aeroelastic Effects}

Achieving high Reynolds number conditions approaching those that are characteristic of flight requires the manipulation of both the total temperature and pressure, as seen in figure 2. As a result, the static aeroelastic deformation of the model, in particular the wing, under load must be considered when attempting to isolate Reynolds number effects. Previous reports for high aspect ratio subsonic transport configurations have shown the static aeroelastic effects to be on the order of Reynolds number effects, and sometimes opposite in sense to that of Reynolds number trends, thus masking the Reynolds number effects. ${ }^{21,22}$ Like the subsonic transport configurations, the current low aspect ratio supersonic transport model is flexible under load, most notably on the thin outboard wing panels.

Video model deformation measurements of the wing under load were concentrated on the outboard wing panel. These measurements indicated that as the aerodynamic load on the wing increased, the outboard wing panel experienced increased washout, similar to that observed on the higher aspect ratio subsonic transports. This type of wing bending occurs because the local lifting center of pressure is located behind the elastic axis of the wing, which produces a local nose-down torsional moment at each outboard wing section. Figure 4 shows representative wing twist data at $\eta=0.922$, relative to the wind-off twist, as a function of dynamic pressure 
and angle of attack. At the higher dynamic pressures and/or higher angles of attack, the magnitude of the local twist change increases (more nose-down) to about 1 to 2 degrees. The relationship between local wing twist change and dynamic pressure is linear for the range of dynamic pressure shown. One would expect that extrapolation to the wind-off condition ( $q=0 \mathrm{psf}$ ) would indicate no twist change; the data at $\alpha=5$ degrees demonstrates this to be the case within the level of measurement uncertainty.

Typical effects of static aeroelastic wing bending on the longitudinal aerodynamic data obtained are presented in figure 5 . These data were obtained with a constant chord Reynolds number of 30 million for several total pressure (dynamic pressure) conditions, as shown in figure 2. The force and moment results show trends consistent with the increasing washout of the wing with increasing load; for a constant body angle of attack, the lift and drag decrease and the nose-up pitching moment increases with increasing dynamic pressure. The change in pitching moment is driven by the significant lift reduction occurring primarily on the outboard wing, which is aft of the moment reference center. The changes in drag are consistent with the reductions in lift. For the transonic data, the lift-curve-slope decreased by approximately $2.5 \%$ at $\alpha=5$ degrees for each configuration over the dynamic pressure range examined. Additionally, the longitudinal stability decreased as the neutral point moved forward by $0.6 \%$ and $0.1 \%$ of the mean aerodynamic chord at $\alpha=5$ degrees for the baseline and transonic cruise configurations, respectively.

The data presented in figure 5 are typical of the increments used to adjust data to 
a constant dynamic pressure to essentially remove static aeroelastic effects from the analysis of Reynolds number effects. The fundamental assumptions in establishing the adjustment increments are: 1) the force and moment variation with dynamic pressure is linear, like the wing twist change, and 2) the sensitivity to dynamic pressure defined at one Reynolds number is valid at other Reynolds numbers. Studies on subsonic transports, and analysis of static aeroelastic sensitivity at other Reynolds numbers for this model support these assumptions. As applied in this paper, force and moment coefficient data were adjusted to nominal dynamic pressures of $1000 \mathrm{psf}$ for the transonic configurations and 270 psf for the take-off configuration. Ideally, an adjustment would be made to shift the coefficient data to the wind-off condition ( $q=0$ psf) to obtain results for the rigid, non-deformed model shape most frequently used in computational simulations. However, the extrapolation to reach the wind-off shape condition introduces additional uncertainty and was not applied herein.

Adjustments for static aeroelastic effects were not applied to any of the wing pressure data presented in this paper. The effect on the wing pressure data was not significant because most of the pressure ports were inboard of the wing leading-edge break $(\eta=0.522)$, where model deformation was minimal.

\section{Reynolds Number Effects}

The primary Reynolds number effects observed for both the take-off and the transonic cruise configurations included skin friction drag reduction and delay of wing leading-edge flow separation onset as the Reynolds number increased. For the 
transonic configurations, an increase in longitudinal stability with increasing Reynolds number was also observed. The following discussion will examine the Reynolds number trends for the longitudinal force and moment coefficients (adjusted for static aeroelastic effects) for the take-off and transonic configurations at specific angles of attack.

\section{Low Speed, High-Lift Conditions}

The Reynolds number effects near the take-off condition are presented in figure 6 for the take-off configuration. In general, drag decreases as the Reynolds number increases, and is accounted for by the theoretical trend of skin friction reduction with Reynolds number. Theoretical skin friction drag for the configuration was calculated with equivalent flat plate theory, plus form factors, using the Blasius and Karman-Schoenherr incompressible skin friction correlations for laminar and turbulent boundary layers, respectively, with compressibility effects accounted for with a reference temperature

method. ${ }^{23}$ As applied herein, the flat-plate theory assumed that the same extent of laminar flow was present on both the upper and lower outboard wing surfaces and that fully turbulent flow existed on both upper and lower surfaces of the inboard wing. All theoretical data was adjusted by a constant increment such that the fully turbulent theoretical curve was anchored to the experimental data at a high Reynolds number condition.

There were two distinct groupings of the measured drag data. One group of data includes Reynolds numbers of 30 million and below (except for the $q=430 \mathrm{psf}$ data at 
$R n=21.6$ million). The second group contains all higher Reynolds number data and the $q=430$ psf data at $R n=21.6$ million. The higher Reynolds number group is associated with an increase in the drag level, like a small bias (about 10 counts), over that of the lower Reynolds number grouping. The bias is illustrated in figure 6 by the increment between the two fully turbulent theoretical curves each anchored by the highest Reynolds number data (fully turbulent) within each data grouping. This drag level increase is attributed primarily to an inward movement of the leading-edge separation at a given angle of attack, which produces a vortex lift effect causing a small force and moment level increment. A sketch illustrating the leading-edge separation movement for this biasing effect is shown in figure 7 , as compared to the outward movement associated with increasing Reynolds number. Within each of these two groupings shown in figure 6, the drag trend with Reynolds number closely follows the classic trends of skin friction with Reynolds number. This is a Reynolds number effect and it is caused by the reduction in skin friction drag as the Reynolds number increases.

In an attempt to understand the 10 count biasing effect observed in the drag data, an analysis of the wing attachment-line boundary layer was performed using representative inboard leading-edge radii at test conditions that span the overlapping regions of the two data groupings. This first order analysis modeled the wing leading edge as a swept circular cylinder to calculate the attachment-line Reynolds number (Rbar). Results from this analysis are presented in figure 8 along with the two lines that separate the range of attachment-line Reynolds number into three boundary-layer state 
regions: laminar, intermittent, and turbulent. The lines defining the interfaces between these regions were adapted from the work of Poll and Paisley. ${ }^{24}$ In figure 8, the attachment-line Reynolds number is calculated for three span-wise stations $(\eta=0.25$, 0.40 , and 0.52 ) that cover the inboard leading edge. As the chord Reynolds number increases, the attachment-line boundary layer progresses from completely laminar at 8.5 million to almost fully turbulent at 50 million. When the attachment-line boundary layer is laminar, it is more susceptible than either a transitional or turbulent one to separation in the strong adverse pressure gradient associated with the leading-edge region. For the attachment-line boundary-layer concept to be consistent with the observed biasing effect for the high Reynolds number data grouping, then some mechanism would need to occur to shift/translate the attachment-line boundary layer to a laminar state, which would cause the leading edge separation to move inboard at those stations where Rbar was shifted to the laminar region. This mechanism would need to either re-laminarize the attachment-line boundary layer, which does not seem likely, or produce a laminar attachment-line boundary layer through a geometric change (smaller effective leading-edge radius). The sensitivity of Rbar to the change in leadingedge radius is also shown in figure 8 as the designed leading-edge radius decreases as $\eta$ increases from 0.25 to 0.52 . Therefore, some mechanism that produces a smaller effective inboard leading-edge radius is believed to cause this unknown biasing effect. A possible mechanism for creating this effective geometric change will be discussed later when the wing middle inboard leading-edge pressures are examined. 
The lift trend with Reynolds number near the take-off condition shows that the lift increases slightly over the range of Reynolds numbers tested. The biasing effect observed in the drag data is not evident in the lift data. This may be caused by either the lift measurement being somewhat less sensitive than the drag measurement or, more likely, the lift distribution on the wing changing with the biasing mechanism such that the net lift remains relatively constant. The overall increase in lift across the Reynolds numbers range is primarily attributed to an improvement in the lift on the outboard wing panels as the leading-edge separation moves outward as illustrated in figure 7. This improvement comes from the increased effectiveness of the outboard wing/flaps camber caused by the delay of the flow separation onset on the inboard wing leading edge. The outward movement of the leading-edge separation with increasing Reynolds number is the same Reynolds number effect as that described for a $65^{\circ}$ delta wing. ${ }^{25,26}$ Note that the inboard leading-edge radius for the supersonic transport model would compare to the medium to large leading-edge bluntness configurations discussed in the $65^{\circ}$ delta wing study.

The pitching moment trends with Reynolds number are also presented in figure 6. As observed in the drag data, the two distinct data groups are also present in the pitching moment data. Within each of these groups, the trend with Reynolds number increase is to develop a more nose-down pitching moment. This nose-down character comes from the outward movement of the inboard leading edge separation, which shifts the center of pressure further behind the moment reference center. This is the same 
Reynolds number effect as discussed above for the lift trend (see figure 7). The noseup level shift between the two data groupings is consistent with an inward movement of the inboard leading edge separation at a given angle of attack, which is caused by the bias effect illustrated in figure 7 .

For reference, the pitching-moment coefficients can be related to the effects of stabilizer deflection. This relationship is presented to give a perspective on the significance of the Reynolds number effect on the pitching-moment coefficient. The stabilizer effectiveness for the full configuration with a tail (when closed aftbody and horizontal tails are present) is approximately a 0.005 change in pitching-moment coefficient for one degree of stabilizer deflection; one major division represents roughly 0.10 degrees of stabilizer deflection to compensate for the pitching moment change. For the take-off configuration, the Reynolds number effect presented in figure 6 is on the order of a 0.4 degrees stabilizer change to balance the additional nose-down pitching moment that develops with the Reynolds number increase.

Since the force and moment data for the high-lift configurations show a fundamental shift in drag and pitching moment levels between two distinct data groupings, two wing pressures are shown to illustrate the consistency in the patterns discussed above. Note that this fundamental shift was not observed in any of the data obtained for any of the transonic configurations.

Typical pressures on or near the wing leading edge as a function of angle of attack are shown in figure 9 for the take-off configuration. The pressure coefficient at $\eta$ 
$=0.405$ is representative of the local flow behavior observed on the blunt inboard wing leading edge. The pressure coefficient at $\eta=0.619$ is representative of the local flow behavior observed near ( 10\% of local chord from the leading edge) the sharper outboard wing leading edge. In general, the inboard leading-edge pressures $(\eta=$ 0.405) were more sensitive to Reynolds number changes than the pressures on the outboard wing panel $(\eta=0.619)$. The outboard wing pressures were less sensitive to Reynolds number changes because of the sharp, outboard wing leading edge. This finding is consistent with that described for the $65^{\circ}$ delta wing study. ${ }^{26}$

For the blunt inboard wing pressures $(\eta=0.405)$, a distinct grouping of the data also exists. In general, the data for Reynolds numbers 30 million and below show that the leading-edge flow stays attached to greater angles of attack than for higher Reynolds numbers. This behavior is not consistent with typical Reynolds number effects and points to some biasing effect. Like the force/moment data, there is one exception to this observed trend. The inboard leading-edge pressure data indicate separation onset at a lower angle of attack for a Reynolds number of 21.6 million and a dynamic pressure of $270 \mathrm{psf}$. However, this same test condition for the force and moment data did not show the same tendency to separate at a lower angle of attack. This observed difference between the pressure and force and moment data for this one test condition occurs because the pressure data was obtained early in the test and then the pressure tubing was removed to conduct the force and moment testing alone at similar test conditions. So, the mechanism causing this biasing effect was not always 
present or effective.

An interesting correlation to tunnel temperature appears that follows these two pressure data groupings. This correlation also is generally true for the force and moment data except for the one test condition mentioned above. The tunnel temperatures associated with the conditions for premature leading-edge separation were -90 degrees Fahrenheit and colder. Although not directly observed, the correlation of this grouping behavior with this temperature range is potentially an indication of frost contamination on the wing inboard leading edge, which could explain the inward movement of the inboard leading-edge separation. Even small accumulations of frost on the inboard wing leading edge has the potential to change the effective leading-edge radius making it appear to be smaller than designed. As the leading-edge radius becomes smaller, the flow will separate at lower angles of attack. $^{25,26}$ The vortex lift increment associated with the increased extent of inboard wing leading-edge separation is consistent with an increased drag level shift as well as a more nose-up pitching moment (vortex lift increase ahead of moment reference center) observed for the high Reynolds number grouping. Keep in mind that even though frost contamination on the wing leading edge was not observed during any of the testing, it was not due to any negligence in the testing procedures. The standard testing procedure includes multiple high, resolution camera views to monitor the model condition during all operations, including surface conditions. However, it is difficult to see surface changes in small, highly curved, wing leading-edge regions especially with 
the variable background lighting within the test section.

The similarity of force, moment, and pressure data trends supports the conclusion that an unconfirmed, systematic bias is affecting the data, but that bias is not Reynolds number dependent. Rather, the bias appears more consistent with a geometric change (smaller effective leading-edge radius). Though clearly having the bias is not desirable, the Reynolds number effects within each group (biased, unbiased) are consistent and observed trends are relevant. As the Reynolds number increases within each group, the drag decrease is consistent with theoretical skin friction reductions. Also, a Reynolds number increase for this type of configuration produces increased lift and a more nose-down pitching moment that is characteristic of an outward movement of the inboard wing leading edge separation.

\section{Transonic Conditions}

The Reynolds number effects for the baseline configuration at conditions near minimum drag are presented in figure 10. Drag decreased as the Reynolds number increased, and is accounted for by theoretical skin friction drag reduction with Reynolds number. Theoretical skin friction drag for the configuration was calculated in the same manner discussed previously in the Low-Speed, High-Lift Conditions section. In figure 10, the open symbols represent experimental data acquired allowing free transition of the wing boundary layer; filled symbols represent experimental data acquired with the wing boundary layer transition fixed near the wing leading edge. Several theoretical curves are included where the variable is the extent of laminar flow on the outboard 
wing panel. All theoretical data was adjusted by a constant increment such that the fully turbulent theoretical curve was anchored to the experimental data for the 80 million Reynolds number conditions. Increments between the theoretical curves indicate the sensitivity of drag to the boundary layer transition location on the outboard wing. From these theoretical curves, the change in chord-wise extent of the laminar boundary-layer region from fully turbulent to $50 \%$ produces a drag level decrease of about 5 counts.

The fully turbulent theoretical skin friction drag trend aligned well with the experimental drag data obtained with the wing boundary layer tripped at low Reynolds number for the baseline configuration. The agreement between the theoretical and the measured drag trends at this angle of attack demonstrates that the change in drag observed is primarily caused by the reduction in skin friction drag. The increment between tripped and transition free data at the lower Reynolds number showed the effects of various extents of laminar boundary layer regions on the outboard wing panels for the baseline configuration. The extent of laminar flow inferred from figure 10 is consistent with temperature sensitive paint measurements of the boundary-layer transition location on the outboard wing panel. ${ }^{27,28}$ The lift and pitching moment trends with Reynolds number presented in figure 10 were essentially constant over the range of Reynolds numbers tested at this angle of attack.

The Reynolds number effects for conditions near the transonic cruise angle of attack are shown in figure 11 for the transonic cruise configuration. In general, the coefficient trends exhibit the same behavior as at the minimum drag condition. The 
change in drag coefficient was roughly the same as that seen at the minimum drag condition in figure 10, suggesting again that skin friction reduction remains the primary influence at this higher angle of attack. As with the minimum drag condition, the Reynolds number effects on lift were not significant near transonic cruise conditions. Additionally, the lift-curve-slope at transonic cruise conditions was not significantly affected by Reynolds number changes. The Reynolds number effect on the pitching moment was larger than that observed at the minimum drag conditions. The data show a nose-down change that would require approximately a 0.3 degrees stabilizer change to compensate for increasing Reynolds number. The increased nose-down character is associated with the outward movement of the inboard wing leading-edge separation (vortex lift effects) with increasing Reynolds number, which improved the lifting characteristics of the outboard wing panel. Additionally, the longitudinal stability increased as the neutral point moved aft by $0.7 \%$ and $0.1 \%$ of the mean aerodynamic chord at $\alpha=5$ degrees for the baseline and transonic cruise configurations, respectively. Note that this Reynolds number effect on neutral point movement is in a direction opposite to that observed for the static aeroelastic effects. Without adjusting for the static aeroelastic effects, the Reynolds number effects on pitching moment behavior is masked.

As mentioned previously, the increased nose-down pitch characteristics at the transonic cruise condition are related to the outward movement of the inboard wing leading-edge separation with increasing Reynolds number. Figure 12 shows the local 
flow behavior on or near the wing leading edge as a function of angle of attack for the transonic configuration in a manner similar to that previously discussed for the take-off configuration. For all configurations, the pressures were more sensitive to Reynolds number changes at the higher angles of attack inboard than outboard, as expected due to the leading-edge shape. The inboard wing leading-edge pressures reach higher suction levels at higher angles of attack as the Reynolds number increases. These higher suction levels are associated with maintaining local leading edge attached flow to higher angles of attack. The Reynolds number effect is the delay of the flow separation onset on the inboard leading edge to higher angles of attack as the Reynolds number increases. Again, the delay of the inboard leading-edge separation at a constant angle of attack with increasing Reynolds number is the same type of flow field character described in the $65^{\circ}$ delta wing studies. ${ }^{25,26}$

\section{CONCLUSIONS}

Wind tunnel tests with a supersonic transport model were conducted in a high Reynolds number facility across a wide range of Reynolds numbers from that available in conventional wind tunnels to near flight conditions at subsonic and transonic Mach numbers. Results were presented which focus on both the Reynolds number and static aeroelastic sensitivities for the longitudinal characteristics of a configuration without a tail. General conclusions are summarized as follows:

1. Static aeroelastic effects are significant. Increasing the dynamic pressure at constant Mach and Reynolds numbers increases the washout of the outboard wing, 
which in turn contributes to a decrease of the lift-curve slope and decreases pitch stability for the transonic configurations.

2. Adjustments for static aeroelastic effects can be determined and applied to isolate pure Reynolds number effects. Static aeroelastic effects can mask Reynolds number effects if not adequately isolated. This is particularly evident in the pitching moment data for all configurations.

3. Reynolds number effects for the configurations at high-lift conditions are generally small. The pitching moment decreases (more nose down) with increasing Reynolds number, which is caused by the outward movement of the inboard wing leading edge separation at a given angle of attack. The drag trend with Reynolds number is dominated by scaleable skin friction correlations.

4. An unknown systematic bias is observed in the force, moment and pressure data for the high-lift configurations. The bias is associated with a non-Reynolds number effect that appears to be connected with some type of inboard wing leading edge change that promotes an inward shift of the inboard wing leading edge separation. Although not directly observed, this leading edge change is potentially associated with wing leading edge frost contamination. The Reynolds number effects with and without this bias are consistent.

5. Reynolds number effects for the configurations at transonic conditions are generally small; lift is insensitive and the pitch stability increases up to $0.7 \%$ of the mean aerodynamic chord. The drag trend with Reynolds number is dominated by 
scaleable skin friction correlations, assuming approximate transition locations are known.

\section{ACKNOWLEDGEMENTS}

The authors would like to thank our many partners from industry and the staff of the NTF for making these tests successful. In particular, we would like to acknowledge Chet Nelson (Boeing), Marvine Hamner (LeaTech, LLC), and Susan Williams (NASAretired) who invested considerable effort over many years towards the development and testing of this model. 


\section{REFERENCES}

${ }^{1}$ McKinney, L.W. and Baals, D.D. (editors), "Wind-Tunnel/Flight Correlation 1981," NASA CP 2225, November 1981.

${ }^{2}$ Haines, A.B., "Scale Effects on Aircraft and Weapon Aerodynamics," AGARD AG-323, 1994.

3"Boundary-Layer Simulation and Control in Wind Tunnels," AGARD AR-224, Report of the Fluid Dynamics Panel Working Group 09, 1988.

${ }^{4}$ Goldhammer, M.E. and Steinle, F.W. Jr., "Design and Validation of Advanced Transonic Wings Using CFD and Very High Reynolds Number Wind Tunnel Testing," $17^{\text {th }}$ ICAS Congress, September 1990.

${ }^{5}$ Lynch, F.T., "Experimental Necessities for Subsonic Transport Configuration Develop-ment," AIAA Paper 92-0158, January 1992.

${ }^{6}$ Bushnell, D.M., Yip, L.P., Yao, C.S., Lin, J.C., Lawing, P.L., Batina, J.T., Hardin, J.C., Horvath, T.J., Fenbert, J.W., and Domack, C.S., "Reynolds Number Influences in Aeronautics," NASA TM 107730, May 1993.

${ }^{7}$ Wilhite, A. W., and Shaw, R. J., "An Overview of NASA's High-Speed Research Program," 20 th ICAS Congress, Paper 112, August 2000.

${ }^{8}$ Nelson, C.P., "Effects of Wing Planform on HSCT Off-Design Aerodynamics," AIAA Paper 92-2629, June 1992.

${ }^{9}$ Wahls, R.A., Owens, L.R., and Rivers, S.M.B., "Reynolds Number Effects on a Supersonic Transport at Transonic Conditions," AIAA Paper 2001-0912, January 2001. 
${ }^{10}$ Owens, L.R., and Wahls, R.A., "Reynolds Number Effects on a Supersonic Transport at Subsonic High-Lift Conditions," AIAA Paper 2001-0911, January 2001.

${ }^{11}$ Gloss, B. B., "Current Status and Some Future Test Directions for the US National Transonic Facility," Wind Tunnels and Wind Tunnel Test Techniques, R. Aeronaut. Soc., 1992, pp. 3.1-3.7.

${ }^{12}$ Igoe, W.B., "Analysis of Fluctuating Static Pressure Measurements in the National Transonic Facility," NASA TP-3475, March 1996.

${ }^{13}$ Bobbitt, C.W., Hemsch, M.J., and Everhart, J.L., "NTF Characterization Status," AIAA Paper 2001-0755, January 2001.

${ }^{14}$ Fuller, D.E., "Guide for Users of the National Transonic Facility," NASA TM83124, 1981.

${ }^{15}$ Foster, J.M. and Adcock, J.B., "User's Guide for the National Transonic Facility Research Data System," NASA TM-110242, April 1996.

${ }^{16}$ Williams, M.S., "Experience with Strain Gage Balances for Cryogenic Wind Tunnels," AGARD-R-774, 1989, pp. 18.1-18.14.

${ }^{17}$ Finley, T.D. and Tcheng, P., "Model Attitude Measurements at NASA Langley Research Center," AIAA Paper 92-0763, 1992.

${ }^{18}$ Burner, A.W., Erickson, G.E., Goodman, W.L., and Fleming, G.A., "HSR Model Deformation Measurements from Subsonic to Supersonic Speeds," 1998 NASA HighSpeed Research Program Aerodynamic Performance Workshop, February 1998, NASA/CP-1999-209692, Vol. 1, p. 1569-1588. 
${ }^{19}$ Braslow, A.L., and Knox, E.C., "Simplified Method for Determination of Critical Height of Distributed Roughness Particles for Boundary-Layer Transition at Mach Numbers from 0 to 5," NACA TN-4363, 1958.

${ }^{20}$ Wahls, R.A., Adcock, J.B., Witkowski, D.P., and Wright, F.L., "A Longitudinal Aerodynamic Data Repeatability Study for a Commercial Transport Model in the National Transonic Facility," NASA TP-3522, August 1995.

${ }^{21}$ Wahls, R.A., Gloss, B.B., Flechner, S.G., Johnson, W.G.,Jr., Wright, F.L., Nelson, C.P., Nelson, R.S., Elzey, M.B., and Hergert, D.W., "A High Reynolds Number Investigation of a Commercial Transport Model in the National Transonic Facility," NASA TM-4418, April 1993.

${ }^{22}$ Al-Saadi, J.A., "Effect of Reynolds Number, Boundary-Layer Transition, and Aeroelasticity on Longitudinal Aerodynamic Characteristics of a Subsonic Transport Wing," NASA TP-3655, September 1997.

${ }^{23}$ Sommer, S.C., and Short, B.J., "Free-Flight Measurements of TurbulentBoundary-Layer Skin Friction in the Presence of Severe Aerodynamic Heating at Mach Numbers from 2.8 to 7.0, NASA TN-3391, March 1955.

${ }^{24}$ Poll, D.I.A., and Paisley, D.J., "On the effect of wing taper and sweep direction on leading edge transition," The Aeronautical Journal of the Royal Aeronautical Society, pp. 109-117, March 1985.

${ }^{25}$ Luckring, J.M., "Reynolds Number and Leading-Edge Bluntness Effects on a 65 Delta Wing," AIAA Paper 2002-0419, January 2002. 
${ }^{26}$ Luckring, J.M., "Transonic Reynolds Number and Leading-Edge Bluntness Effects on a 65 Delta Wing," AIAA Paper 2003-0753, January 2003.

${ }^{27}$ Hamner, M.P., "Demystifying Luminescent Paint Technology, A Guide for NonDevelopers," AIAA Paper 2001-2981, June 2001.

${ }^{28}$ Hamner, M.P., Popernack, Jr., T.G., Owens, L.R., and Wahls, R.A., "Using Temperature Sensitive Paint Technology," AIAA Paper 2002-0742, January 2002. 


\section{TABLES}

\begin{tabular}{ll}
\hline \hline \multicolumn{1}{c}{ Ratios } & Values \\
\hline $\begin{array}{ll}\text { Model wing reference area to } \\
\text { NTF cross-sectional area }\end{array}$ & 0.0515 \\
Model span to NTF test section width & 0.3478 \\
Model frontal area to NTF cross- & \\
sectional area ( $\alpha=0$ degrees) & 0.0022 \\
\hline \hline
\end{tabular}

Table 1. Model size relative to the NTF test section.

\begin{tabular}{lll}
\hline \hline Designation & $\begin{array}{l}\text { LE Deflection, } \\
\text { degrees } \\
\text { Inboard/Outboard }\end{array}$ & $\begin{array}{l}\text { TE Deflection, } \\
\text { degrees } \\
\text { Inboard/Outboard }\end{array}$ \\
\hline Baseline & $0 / 0$ & $0 / 0$ \\
Take-Off & $30 / 30$ & $10 / 10$ \\
Landing & $30 / 30$ & $20 / 20$ \\
$\begin{array}{l}\text { Stall Recovery } \\
\text { Transonic }\end{array}$ & $50 / 50$ & $30 / 30$ \\
Cruise & $0 / 10$ & $0 / 3$ \\
\hline \hline
\end{tabular}

Table 2. Available Wing Configurations. 


\section{CAPTIONS}

Figure 1. Supersonic transport model.

Figure 2. NTF operational envelopes.

Figure 3. Representative longitudinal force and moment data.

Figure 4. Outboard wing twist change under load for transonic cruise configuration, $M=0.90$.

Figure 5. Static aeroelastic effects on longitudinal coefficients, referenced to $q=1000 \mathrm{psf}$, $\mathrm{M}=0.90$.

Figure 6. Longitudinal coefficient trends with Reynolds number, near take-off point, $M=0.30$.

Figure 7. Leading-edge separation movement with systematic bias and with Reynolds number increase.

Figure 8. Wing attachment-line boundary-layer analysis similar to that of Poll and Paisley (ref. 24) using test conditions and inboard leading-edge geometry relevant to the current study.

Figure 9. Wing leading-edge pressure characteristics for take-off configuration, $M=0.30$.

Figure 10. Longitudinal coefficient trends with Reynolds number for baseline configuration, near minimum drag, $\mathrm{M}=0.90$.

Figure 11. Longitudinal coefficient trends with Reynolds number for transonic cruise configuration, near transonic cruise, $\mathrm{M}=0.90$.

Figure 12. Wing leading-edge pressure characteristics for transonic cruise configuration, $M=0.90$. 


\section{FIGURES}

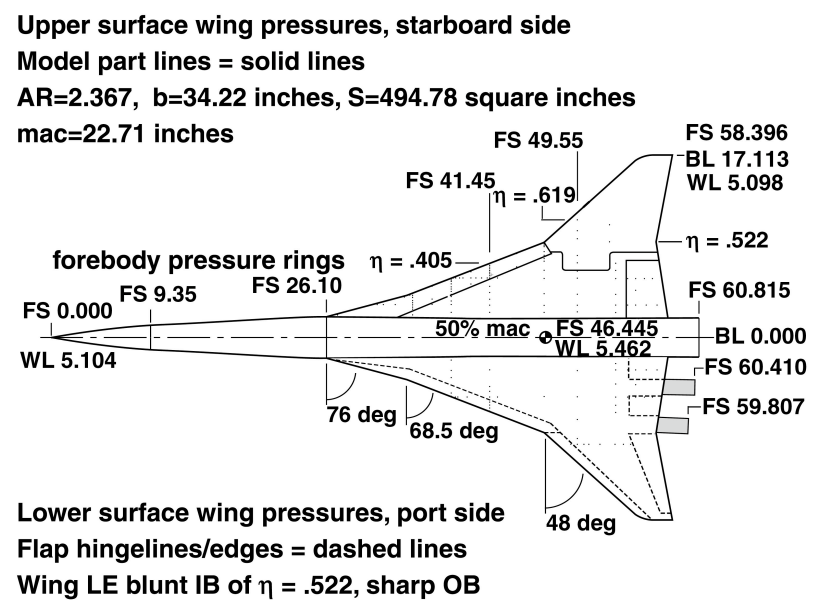

a) Model drawing with pressure locations (linear dimensions in inches).

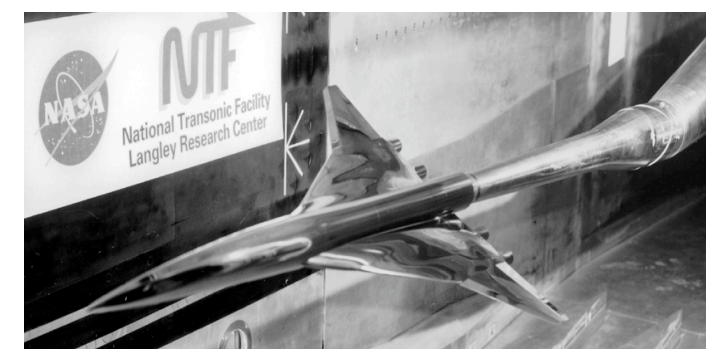

b) $2.2 \%$ Reference $\mathrm{H}$ model in the NTF.

Figure 1. Supersonic transport model. 


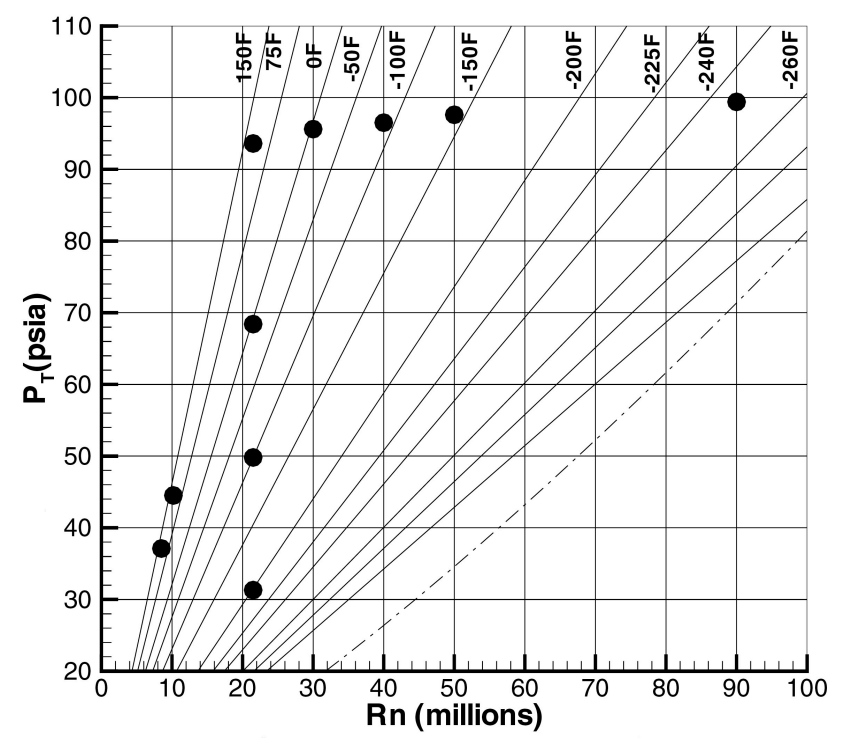

a) Mach $=0.30$

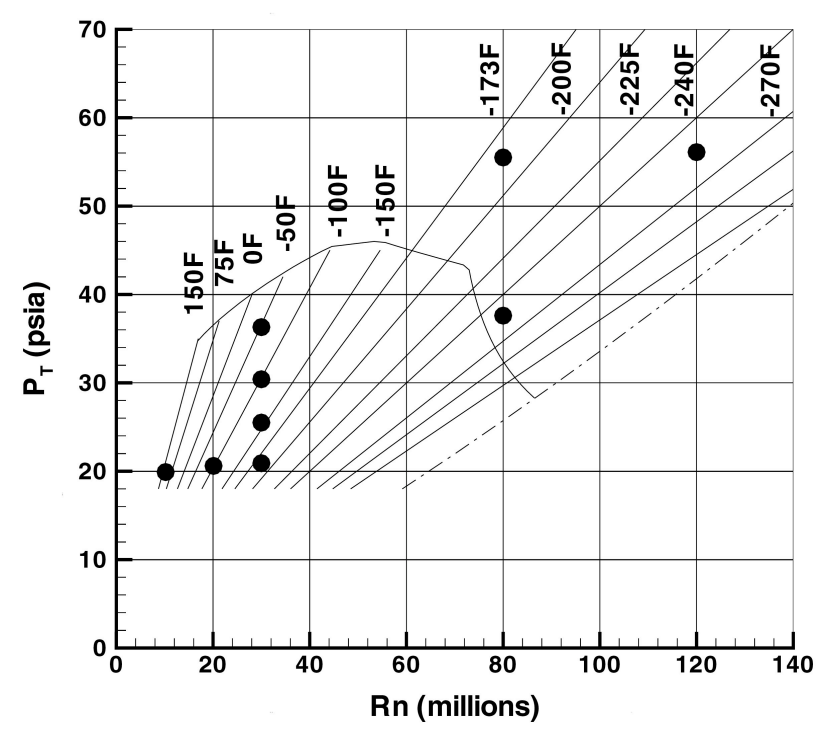

b) Mach $=0.90$

Figure 2. NTF Operational envelopes. 

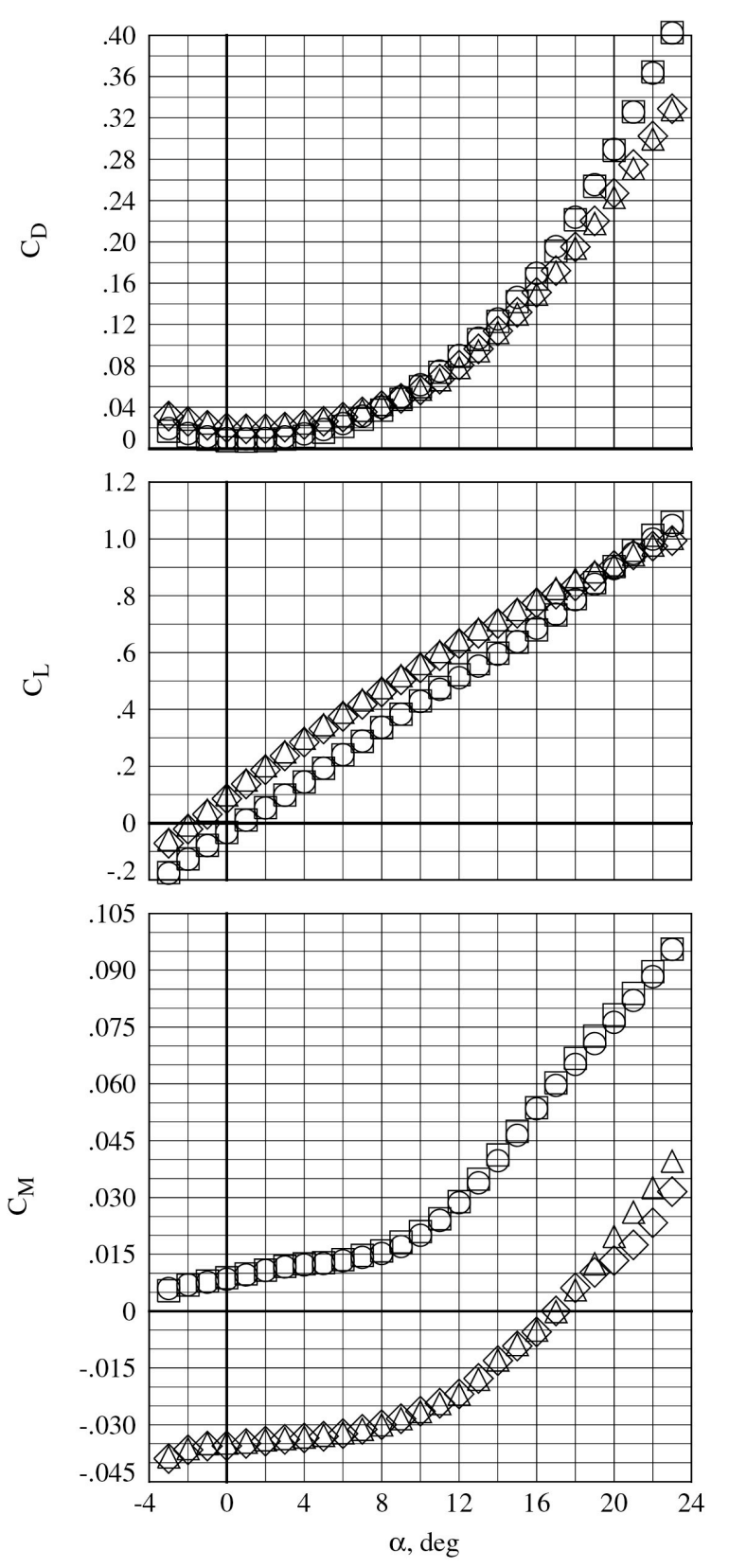

$\begin{array}{cllc} & \text { Rn (millions) } & \text { q, psf } & \text { config } \\ \bigcirc & 8.5 & 318 . & \text { Baseline + nac } \\ \square & 90.0 & 839 . & \text { Baseline + nac } \\ \triangle & 8.5 & 318 . & \text { Take-off + nac } \\ \triangle & 89.9 & 842 . & \text { Take-off + nac }\end{array}$

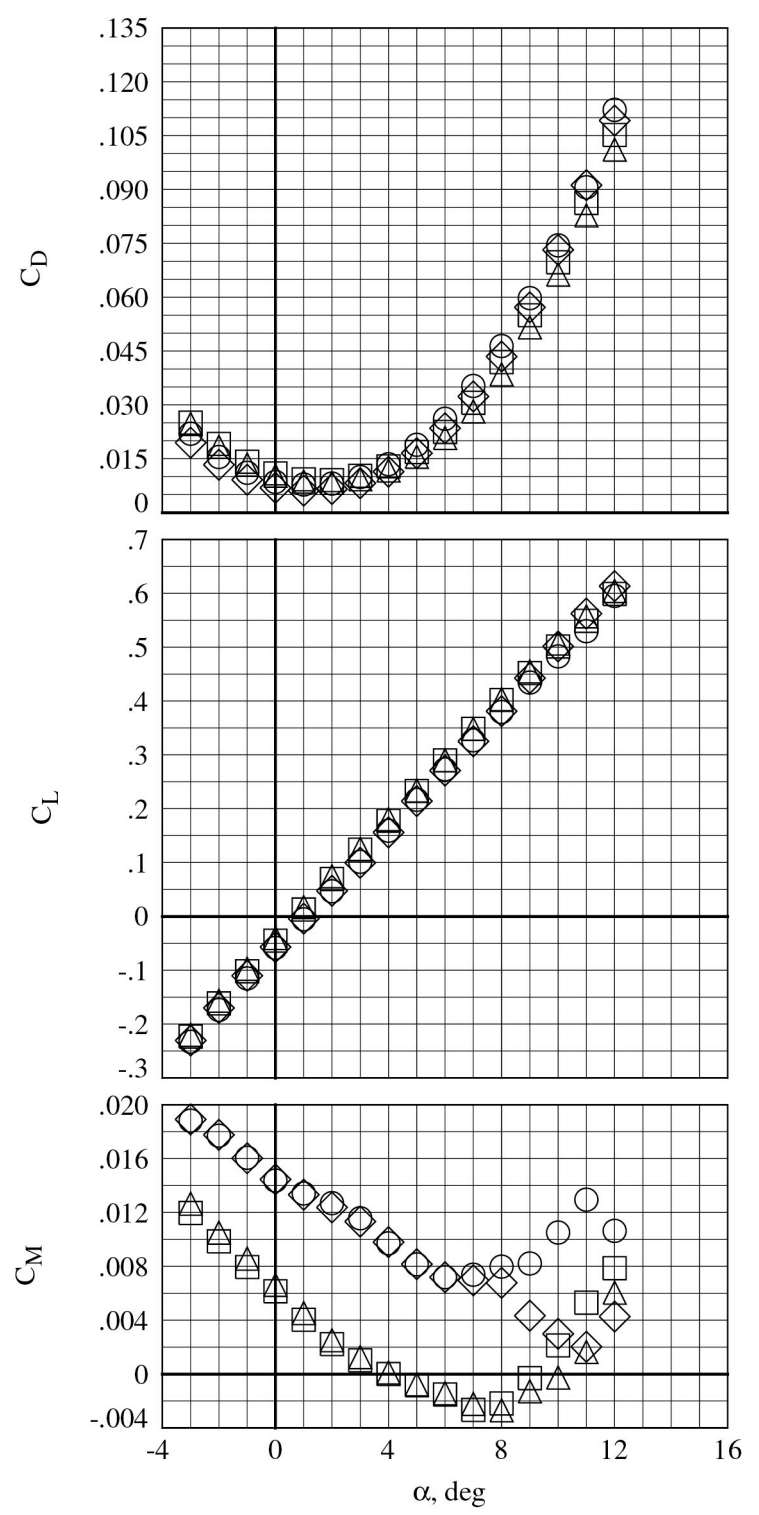

Rn (millions) q, psf config

○ $\quad 10.2 \quad 967 . \quad$ Baseline + nac

$\square \quad 10.2 \quad 963 . \quad$ Transonic + nac

$\diamond \quad 79.6 \quad$ 1797. Baseline + nac

$\triangle \quad 79.5 \quad 1802 . \quad$ Transonic + nac

b) Transonic configurations, $M=0.90$

a) High-lift configurations, $M=0.30$

Figure 3. Representative longitudinal force and moment data. 

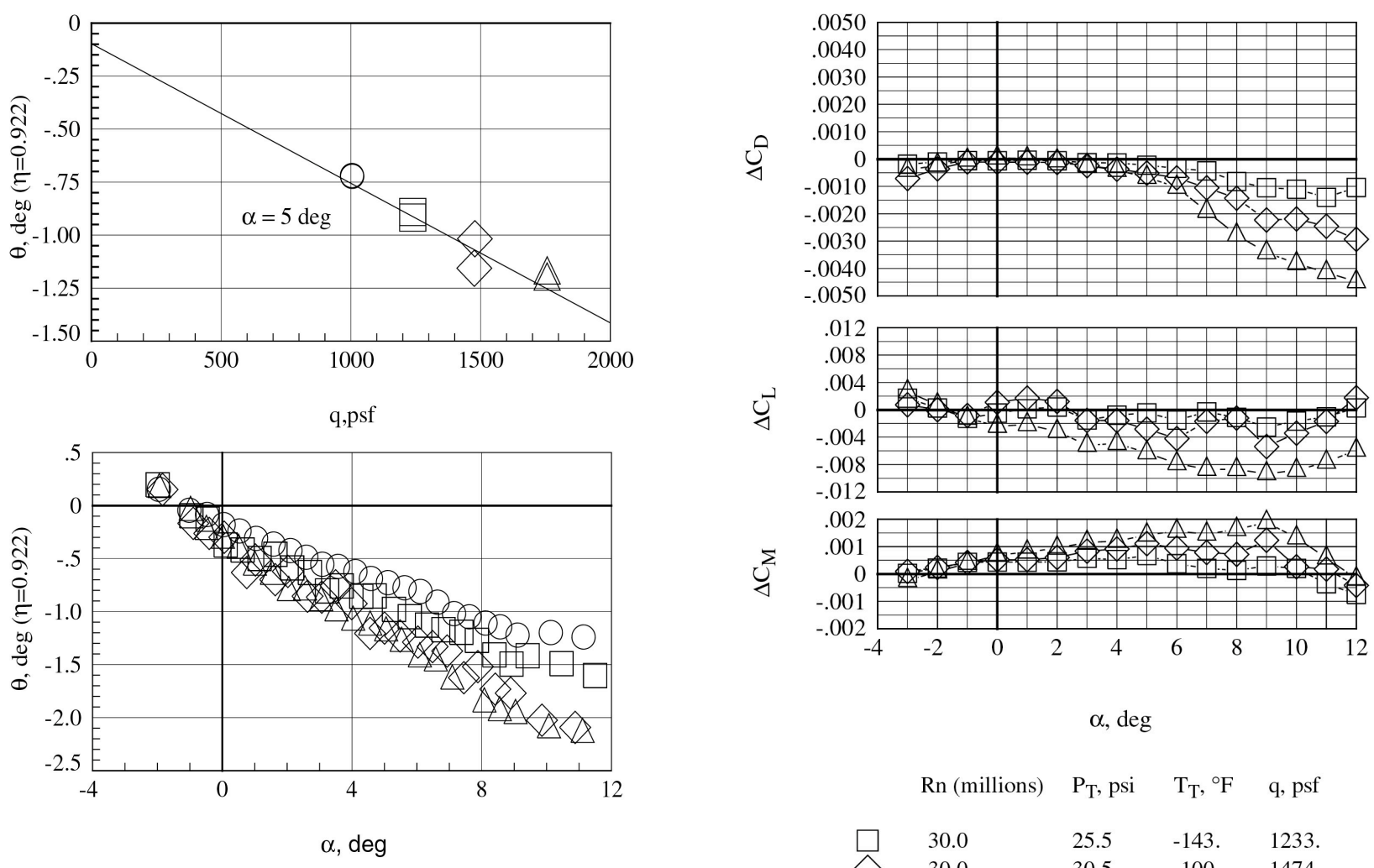

$$
\alpha, \operatorname{deg}
$$

Rn (millions) $\quad \mathrm{P}_{\mathrm{T}}$, psi $\quad \mathrm{T}_{\mathrm{T}},{ }^{\circ} \mathrm{F} \quad \mathrm{q}$, psf

\begin{tabular}{|c|c|c|}
\hline 30.0 & 25.5 & -143 \\
\hline 30.0 & 30.5 & -100 \\
\hline 30.0 & 36.4 & -51 \\
\hline
\end{tabular}

Figure 5. Static aeroelastic effects on longitudinal coefficients, referenced to $q=1000$ psf, $M=0.90$.

Figure 4. Outboard wing twist change under load for transonic cruise configuration, $\mathrm{M}=\mathbf{0 . 9 0}$. 

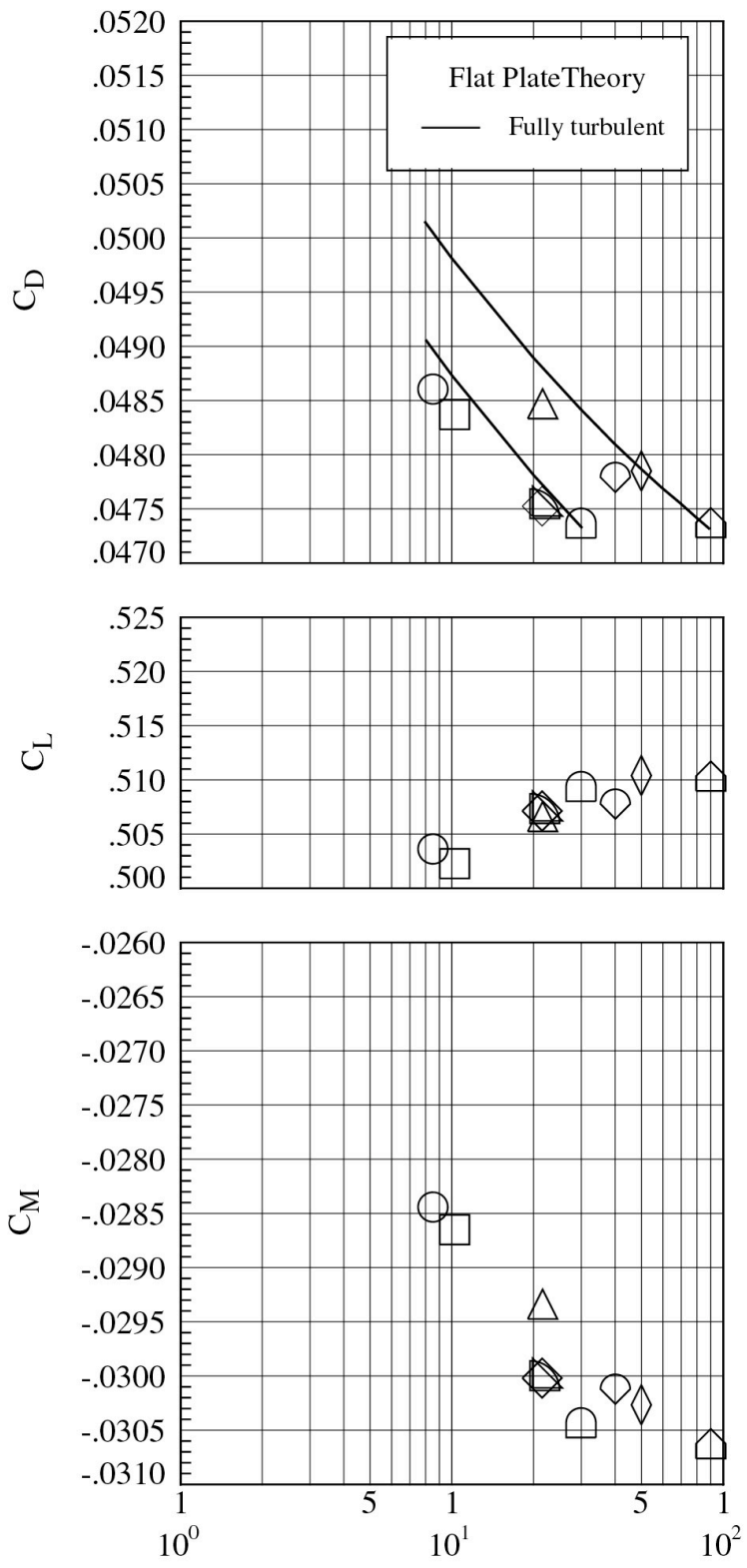

Rn (millions)

$\begin{array}{ccccl}\alpha, \text { deg } & \text { Rn (millions) } & \text { q, psf } & \mathrm{P}_{\mathrm{T}}, \mathrm{psi} & \mathrm{T}_{\mathrm{T}},{ }^{\circ} \mathrm{F} \\ & & & & \\ 9.0 & 8.5 & 318 . & 37.1 & 120 . \\ 9.0 & 10.2 & 383 . & 44.5 & 120 . \\ 9.0 & 21.5 & 267 . & 31.3 & -201 . \\ 9.0 & 21.6 & 427 . & 50.0 & -100 . \\ 9.0 & 21.5 & 588 . & 68.7 & -4 . \\ 9.0 & 21.5 & 806 . & 93.8 & 120 . \\ 9.0 & 29.9 & 818 . & 95.3 & -4 . \\ 9.0 & 40.0 & 828 . & 96.3 & -90 . \\ 9.0 & 49.9 & 834 . & 97.2 & -143 . \\ 9.0 & 89.9 & 842 . & 99.4 & -247 .\end{array}$

Figure 6. Longitudinal coefficient trends with Reynolds number, near take-off point, $\mathrm{M}=\mathbf{0 . 3 0}$.

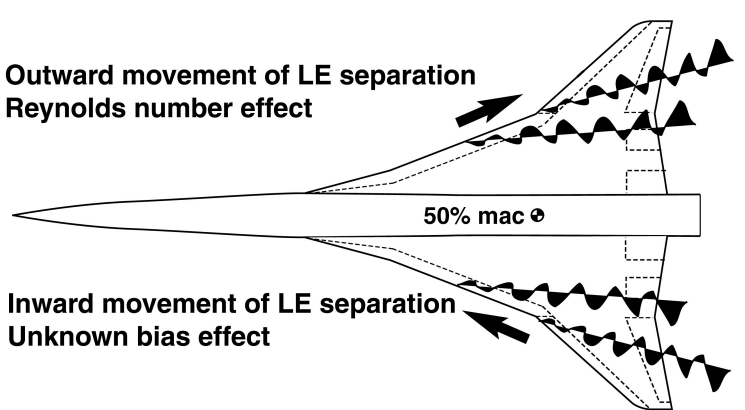

Figure 7. Leading-edge separation movement with systematic bias and with Reynolds number increase.

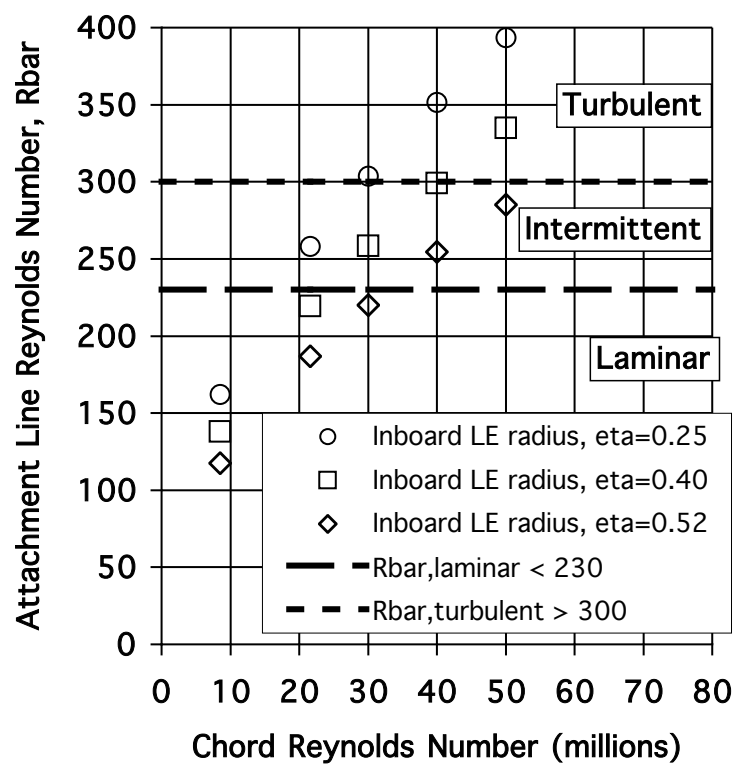

Figure 8. Wing attachment-line boundarylayer analysis similar to that of Poll and Paisley (ref. 24) using test conditions and inboard leading-edge geometry relevant to the current study. 

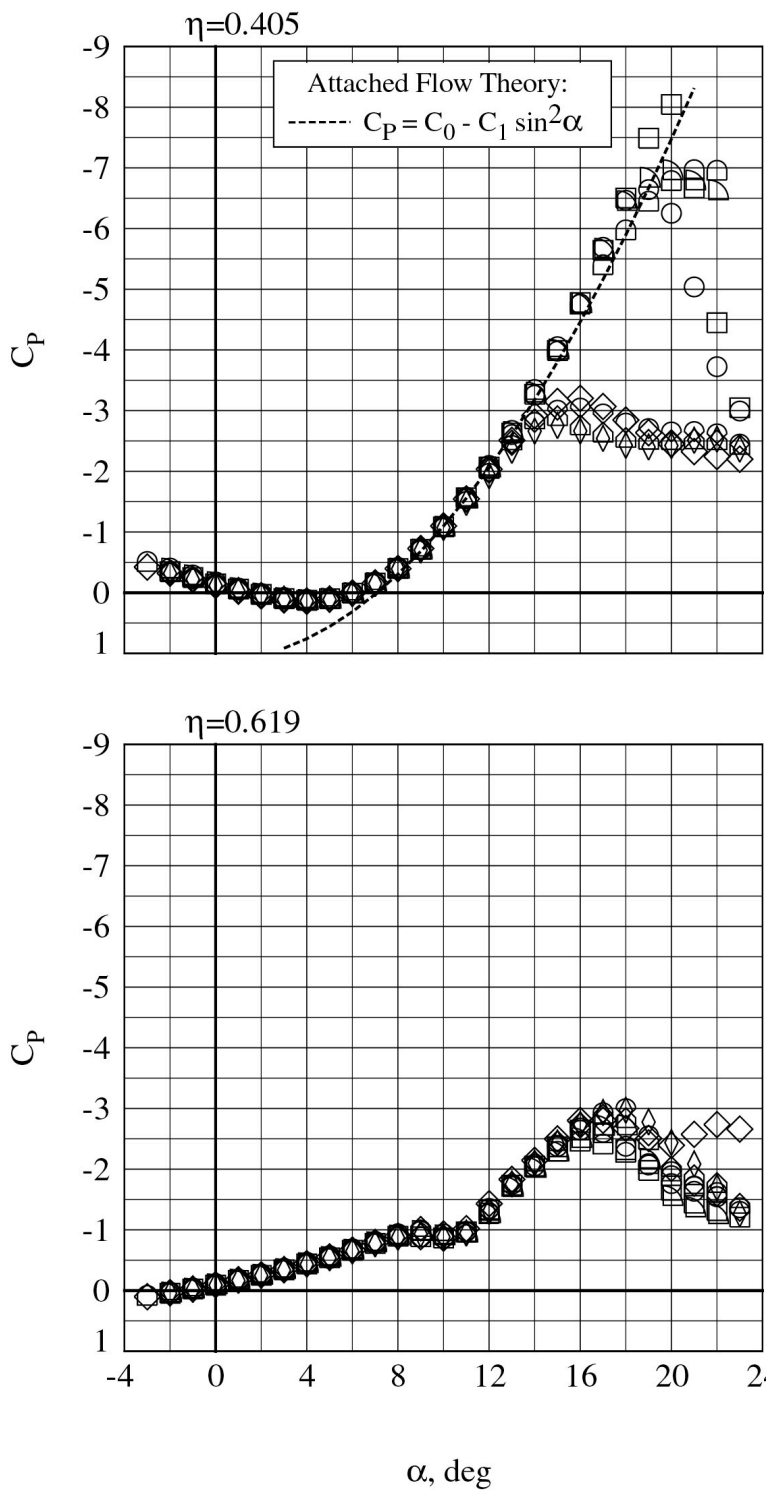

$\begin{array}{llll} & \text { Rn (millions) } & \text { q, psf } & \mathrm{T}_{\mathrm{T}},{ }^{\circ} \mathrm{F} \\ & & & \\ \square & 8.5 & 317 . & 120 . \\ \diamond & 10.2 & 381 . & 120 . \\ \triangleright & 21.6 & 268 . & -201 . \\ \square & 21.5 & 803 . & 120 . \\ \diamond & 29.9 & 818 . & -4 . \\ \diamond & 39.9 & 825 . & -90 . \\ \Delta & 49.9 & 835 . & -143 . \\ & 90.0 & 841 . & -247 .\end{array}$

Figure 9. Wing leading-edge pressure characteristics for take-off configuration, $\mathrm{M}=\mathbf{0 . 3 0}$.
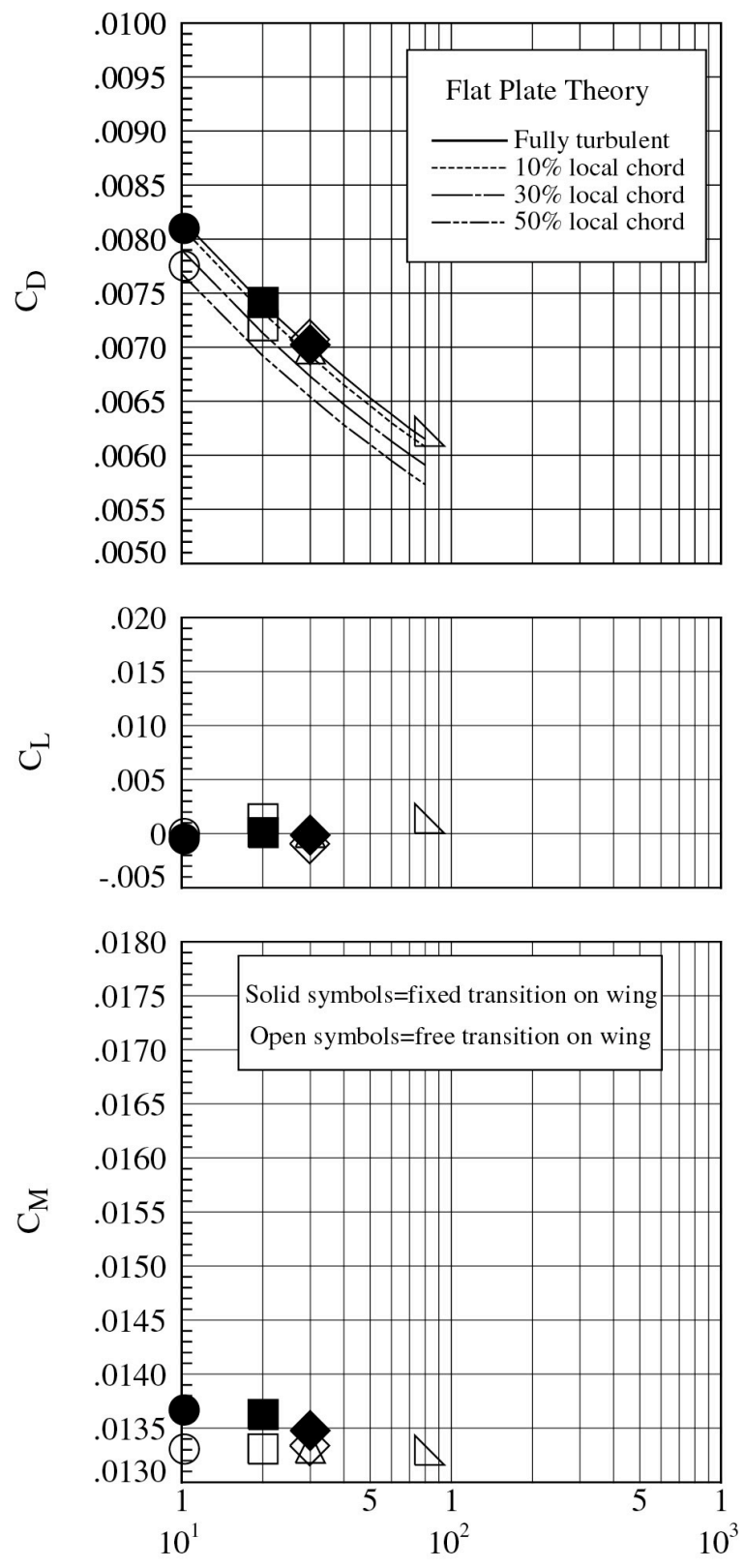

Rn (millions)

$\alpha$, deg Rn (millions) q, psf $\mathrm{P}_{\mathrm{T}}$, psi $\quad \mathrm{T}_{\mathrm{T}},{ }^{\circ} \mathrm{F}$

$\begin{array}{llllll}\bigcirc & 1.1 & 10.2 & 967 . & 20.0 & 121 . \\ \square & 1.1 & 20.0 & 994 . & 20.6 & -97 . \\ \triangle & 1.1 & 29.8 & 1003 . & 20.8 & -184 . \\ \triangle & 1.1 & 30.0 & 1755 . & 36.3 & -52 . \\ \triangle & 1.1 & 79.6 & 1797 . & 37.3 & -249 .\end{array}$

Figure 10. Longitudinal coefficient trends with Reynolds number for baseline configuration, minimum drag, $\mathbf{M}=\mathbf{0 . 9 0}$. 

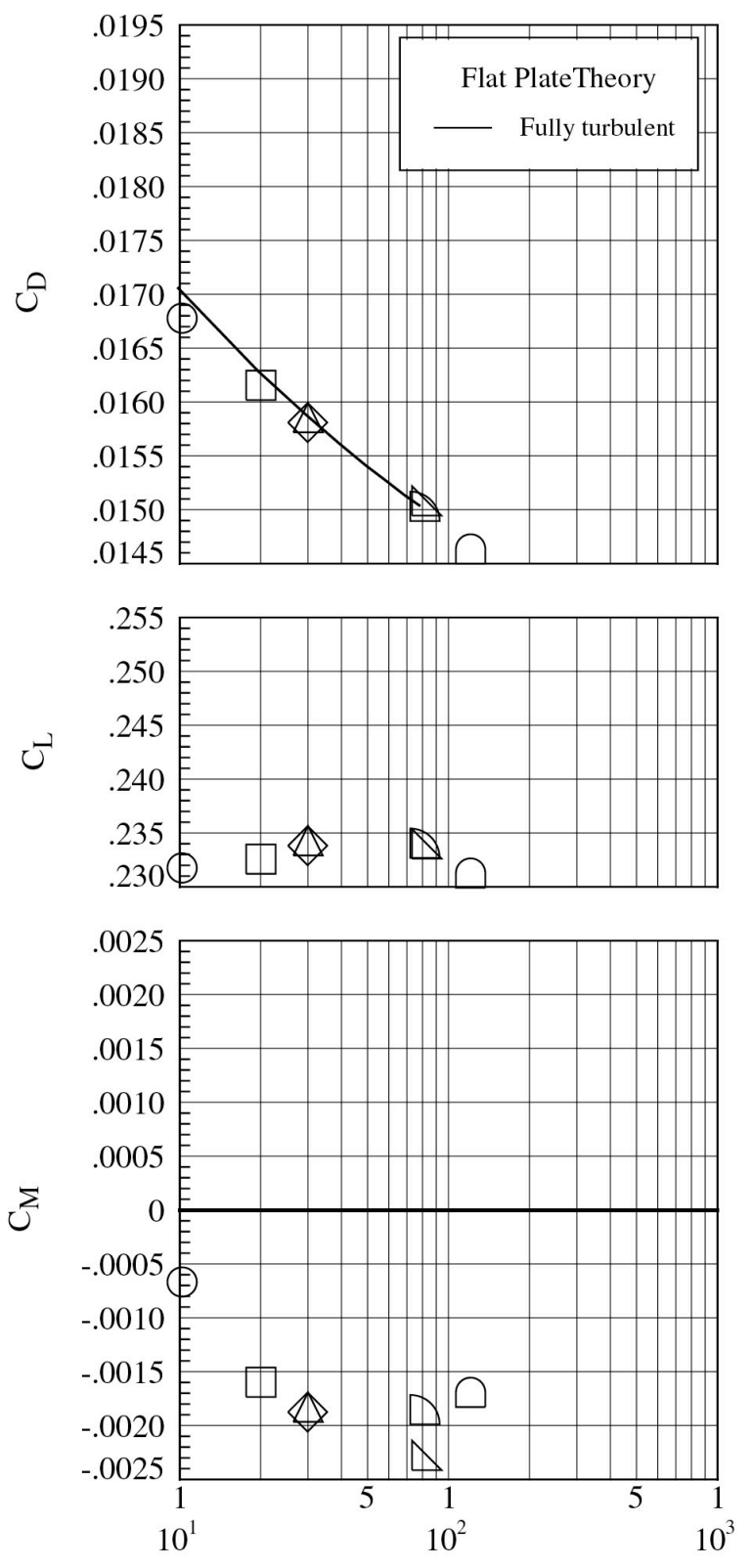

Rn (millions)

$\begin{array}{cccccc} & \alpha \text {, deg } & \text { Rn (millions) } & \text { q, psf } & \mathrm{P}_{\mathrm{T}}, \mathrm{psi} & \mathrm{T}_{\mathrm{T}},{ }^{\circ} \mathrm{F} \\ \bigcirc & 5.0 & 10.2 & 963 . & 19.9 & 120 . \\ \square & 5.0 & 20.0 & 995 . & 20.6 & -97 . \\ \bigotimes & 5.0 & 29.9 & 1005 . & 20.8 & -184 . \\ \triangle & 5.0 & 30.0 & 1755 . & 36.3 & -52 . \\ \triangle & 5.0 & 79.5 & 1802 . & 37.3 & -249 . \\ \square & 5.0 & 80.0 & 2677 . & 55.5 & -185 . \\ \square & 5.0 & 120.8 & 2704 . & 56.1 & -250 .\end{array}$

Figure 11. Longitudinal coefficient trends with Reynolds number for transonic cruise configuration, near transonic cruise, $\mathbf{M}=\mathbf{0 . 9 0}$.
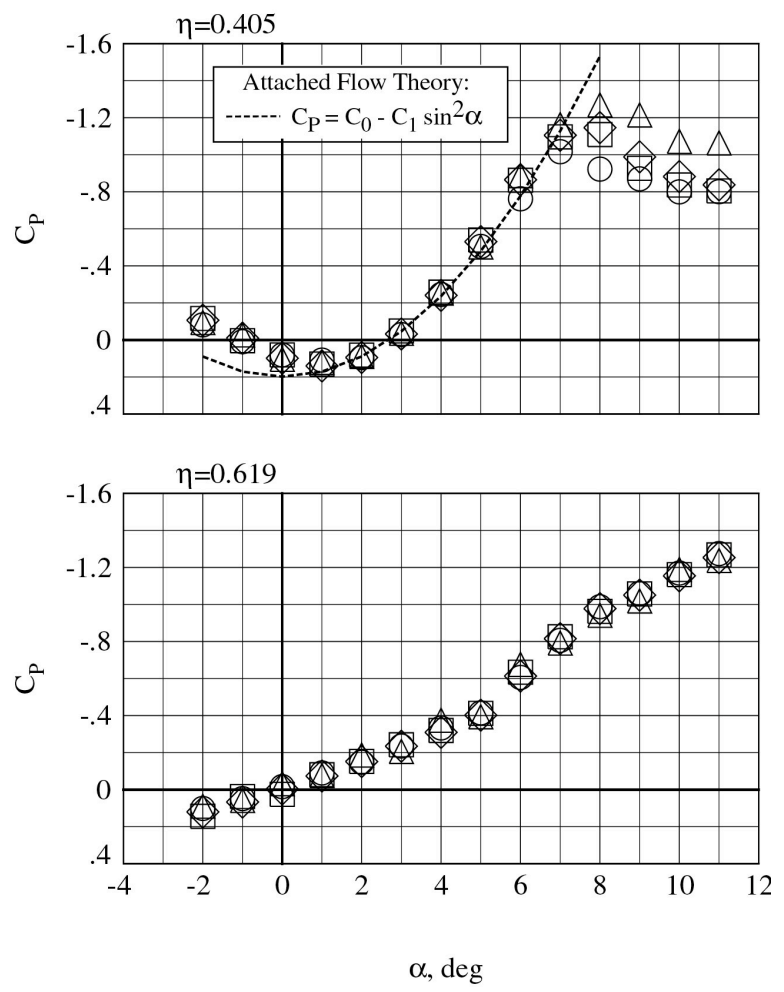

$$
\begin{array}{cccc} 
& \text { Rn (millions) } & \text { q, psf } & \mathrm{T}_{\mathrm{T}},{ }^{\circ} \mathrm{F} \\
\bigcirc & 10.2 & 967 . & 120 . \\
\square & 20.0 & 996 . & -97 . \\
\triangle & 30.0 & 1007 . & -184 . \\
\triangle & 79.7 & 1797 . & -250 .
\end{array}
$$

Figure 12. Wing leading-edge pressure characteristics for transonic cruise configuration, $\mathrm{M}=\mathbf{0 . 9 0}$. 